\title{
Report on Study Tour Programme of IVLP in Madanapalli Cluster
}

\author{
Dr. P. M. Muniswamy Reddy ${ }^{1}$, M. Ramesh ${ }^{2}$ \\ ${ }^{1}$ Silkworm Seed Production Centre, NSSO, Central Silk Board, Madanapalli-517325, A.P
}

\begin{abstract}
The Institute Village Linkage Programme (IVLP) implementation of biovltine double hybrids silkworm rearing and technology transfer, considering the needs of the end users/beneficiaries in Madanapallicluster. Sericulture is one of the most important rural industries practiced since several decades. It has certain inherent advantages of bivoltine double hybrids rearing in Madanapalli area through. "Institute Village Linkage Programme" (IVLP) Central Silk Board, XII Plan for implementation of Bivoltine Double Hybrids which has resulted in improvement in the productivity levels of beneficiary farmers.
\end{abstract}

Keywords: IVLP, Bivoltine, Double Hybrids, Silkworm Rearing, Mulberry

\section{Introduction}

IVLP study tour progremme organized SSPC Madanapalli cluster. In this regards we are divided into two batches (Total 100farmers) one batch each 50 farmers the first batch tour programme on 20.02.2016. Finely we selected two villages at Bangarpet Taluk, Kolar Dist. Karnataka State. In this villages they are maintained very systematically mulberrygarden and different spacing 9x9 feet (row to row) (plant to plant) $3 \times 3$ feet this is one of the newly well-established adopted technology mulberry plantation gardens and verity V1\& S36 only. Hythadalahalli progressive farmers Mr Purshotham, Mr. Srinivasa and Mr. Ramesh, expressed about mulberry garden maintenance selection of land, thoroughly deep ploughing using tractors and maintained suitable spacing, raw system and pit system raising of nursery plantation(saplings) minimum 06-10 months, apply required quantity of manures FYM and complex bio fertilizers etc., and frequently irrigation required.

Rearing of Bivoltine Silkworm: It is one of the most important first step thoroughly disinfect the rearing house and appliances using commercially available disinfectants like bleaching powder, sanitech, Asthra, Decal etc., using powder spryer after completion of the cocoon harvesting and they expressed maintenance hygienic condition in and around the rearing house in summer using wet gunny cloths or by drip system to avoid the hot air into the rearing house.

Rearing maintenance of leaf quality, feeding, bed spacing, cress ventilation, care during moulting stage using lime and bed disinfections applied systematically and using plastic mount ages for spinning. Using plastic mount age it is very economical viable to harvest cocoons and to maintain good quality of cocoons to best competitive price in the market and good yield per 100dfle 90kgs. They reared ever month crop they divided two or three plates (year 10crops).

Hosakote Village progressive farmers Mr. Krishnappa, Mr. Badrappa, Mr. Suresh and Mr. Venkateshappa are expressed about mulberry gardens and bivoltine double hybrid silkworm rearing it is one of the main sources of income in our livelihood for surviving the families and they are involved totally in sericulture practices.

Though all farmers are well established mulberry gardens in different spacing like paired row and newly developed 9x9feet single row system (row to row) (plant to plant) $3 \times 3$ feet and also inter crop system cultivation adopted it produced robust leaf quality and maintained good mulberry gardens using proper quantity of Farm yard manure (FYM) and complex manures also using micronutrients (Seri bust) bio fertilizers for required quantity and drip irrigation it was low water yield even though they reared good quantity per 100dfls yield 90kgs and best competitive price in market. They reared ever month crop they divided two or three plates (year 10crops)

Finally our IVLP farmers are interacted with them to discuss about the methodologies to maintain the mulberry garden package of practices and to produce good quality of mulberry leaf and silkworm rearing technologies disease and pests' management and control the disease to maintain hygienic condition in silkworm rearing house and good quality of cocoons harvesting practices in sericulture industry.

Finely all our farmers are very happy and thanks them they are explained all Seri cultural activities very nicely to brief local language how to maintain mulberry gardens in different spacing and silkworm rearing technologies and using of plastic montages etc.;

\section{Conclusion}

It is concluded from the present study that the imparting bivoltine double hybrid silkworm rearing and farmers would enhance their knowledge and cocoon quality about the improved and recommended technology adoption in the field and ultimate the cocoon yield and cocoon price earning of the bivoltine silkworm rearing beneficiaries Therefore this IVLP programme has a positive impact on their adoption of improved technologies and their knowledge level. Through this they can earn for their better livelihood and look after their families by 


\section{International Journal of Science and Research (IJSR) \\ ISSN (Online): 2319-7064}

Index Copernicus Value (2013): 6.14 | Impact Factor (2015): 6.391

increasing their annual income through bivoltine double hybrid silkworm rearing.

IVPL Study Tour Programme of at Hythadlahalli \& Hosakotebangarapettaluk Kolar Karnataka
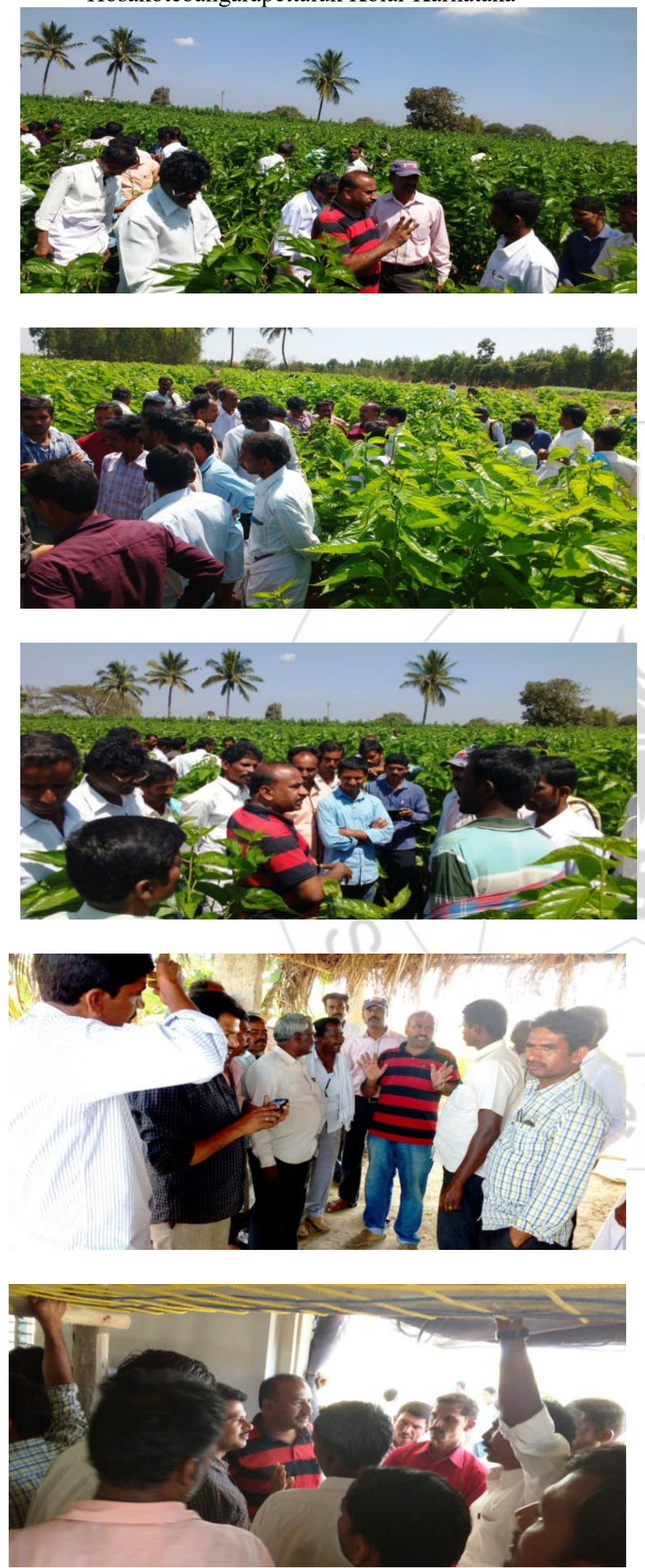
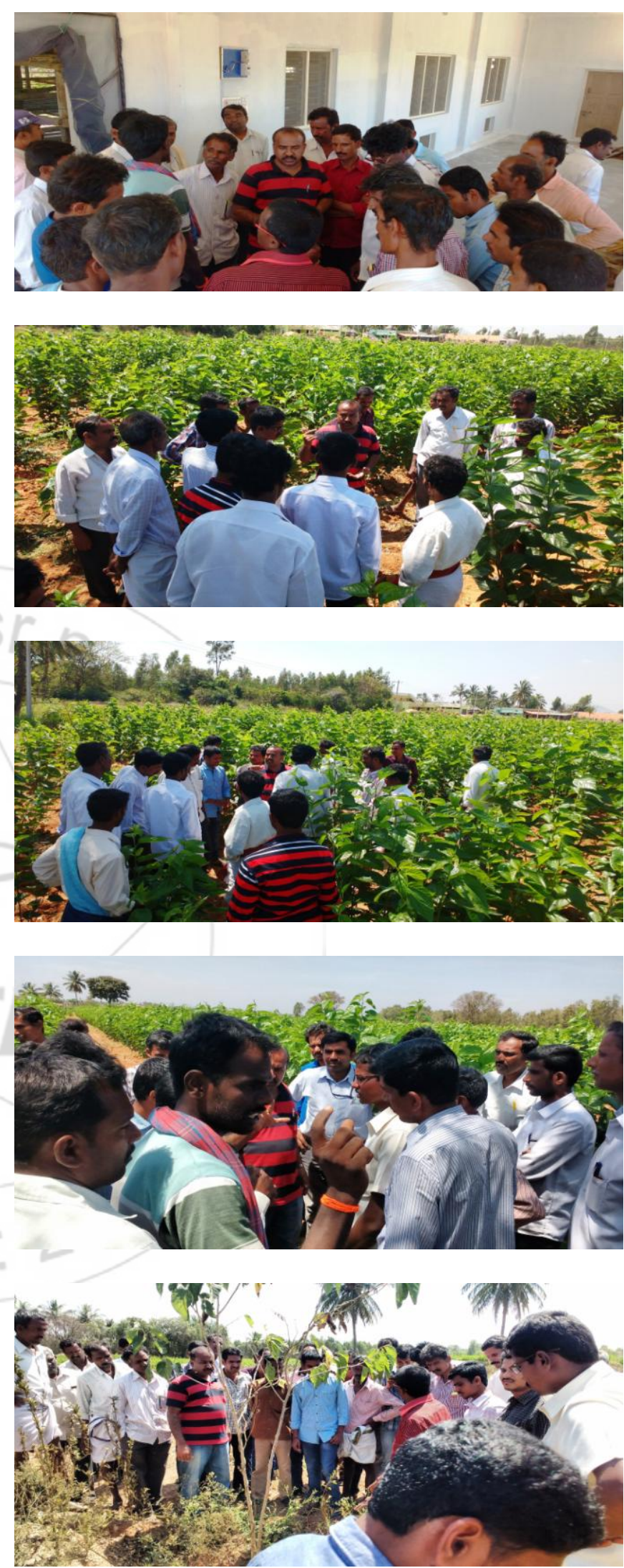
International Journal of Science and Research (IJSR)

ISSN (Online): 2319-7064

Index Copernicus Value (2013): 6.14 | Impact Factor (2015): 6.391
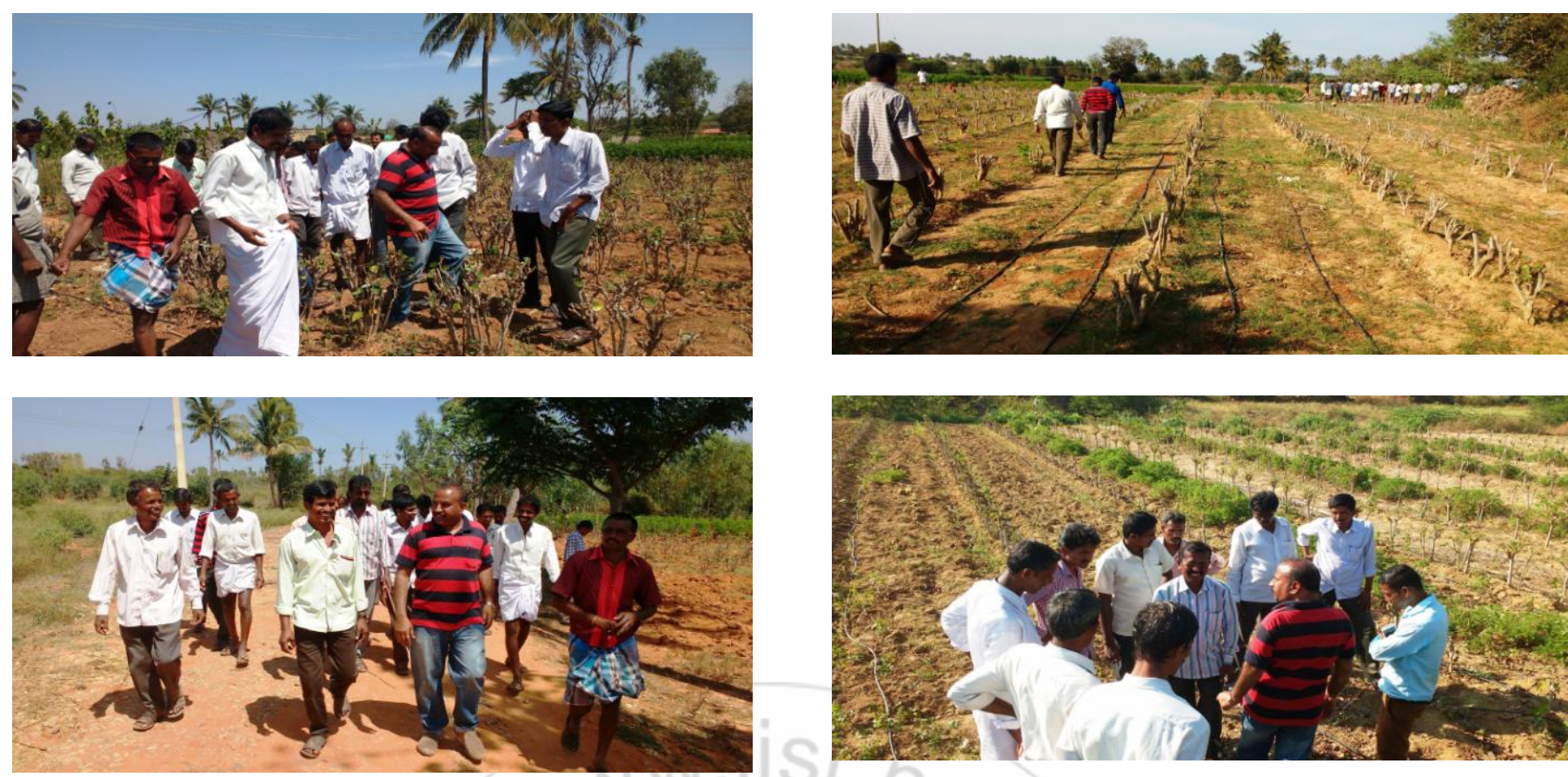

Photographs of Study Tour of IVPL at Hosakotebangarapet
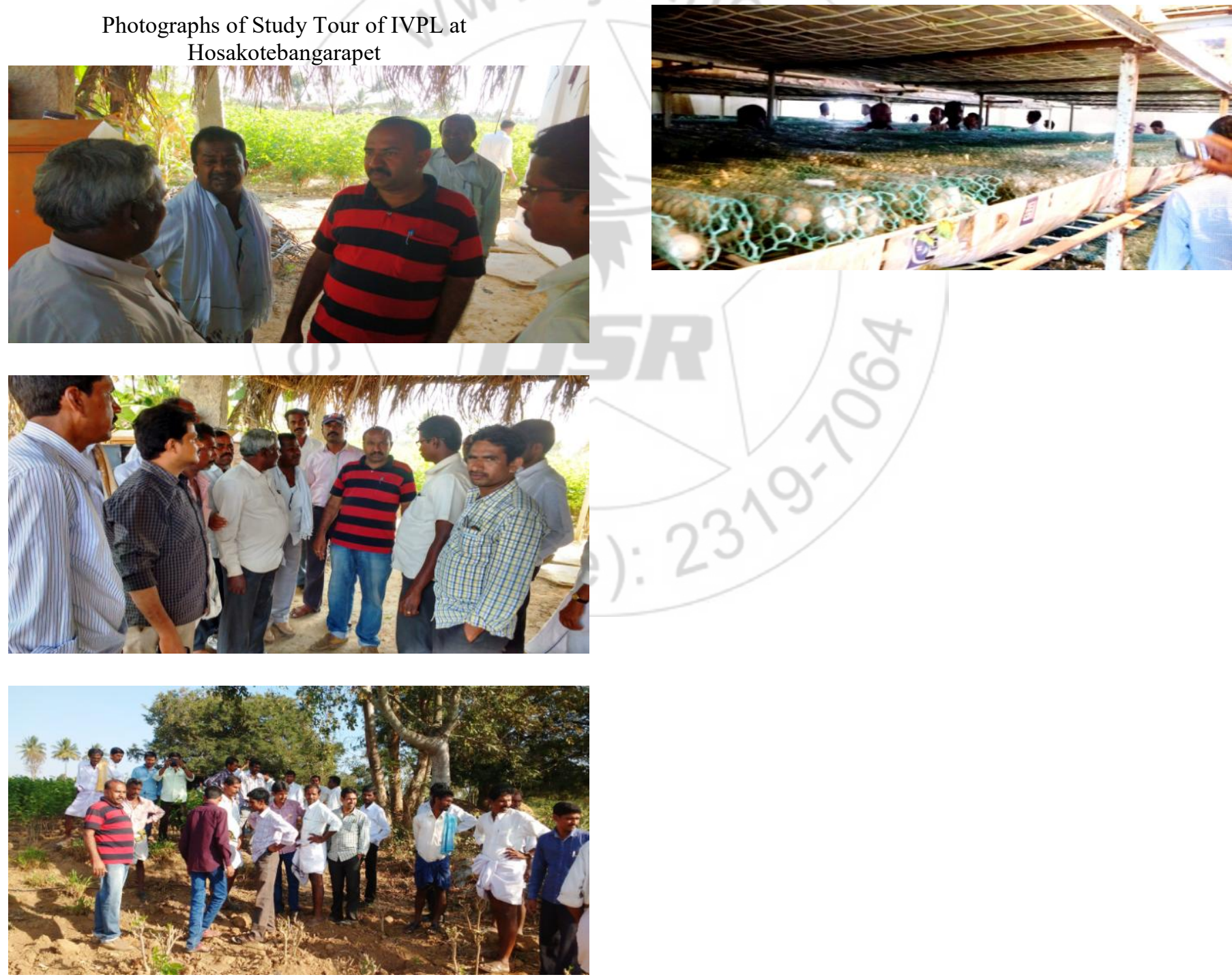

Volume 5 Issue 5, May 2016

www.ijsr.net 